\title{
EKOLABELING AS DEVELOPMENT FACILITATOR OF THE Environmentally Oriented Product Policy
}

\author{
Ruzena Kralikova, Miroslav Rusko \& Emil Wessely
}
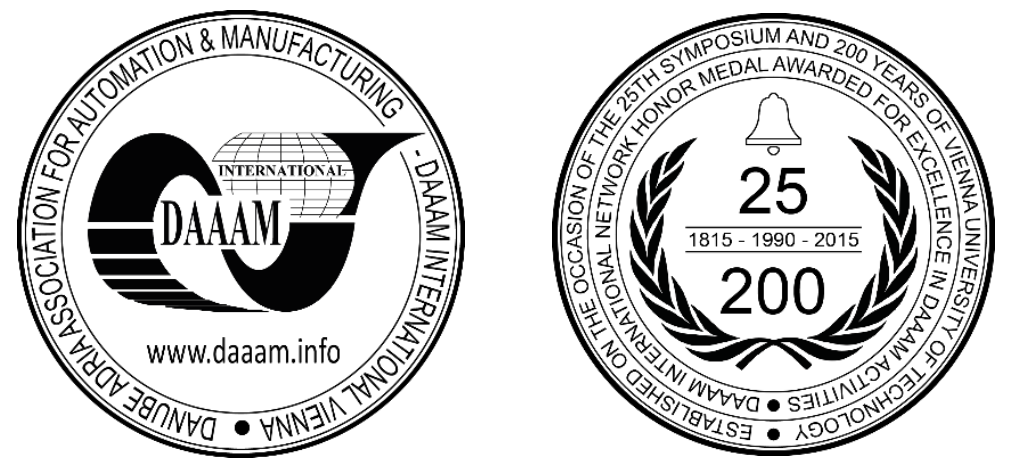

This Publication has to be referred as: Kralikova, R[uzena]; Rusko, M[iroslav] \& Wessely, E[mil] (2017). Ekolabeling as Development Facilitator of the Environmentally Oriented Product Policy, Proceedings of the 28th DAAAM International Symposium, pp.0124-0130, B. Katalinic (Ed.), Published by DAAAM International, ISBN 978-3-90273411-2, ISSN 1726-9679, Vienna, Austria

DOI: $10.2507 / 28$ th.daaam.proceedings.016

\begin{abstract}
Products available on the market should be healthiness and should not threaten human life and the overall safety of the consumer and does not pollute the environment. This means that security specifications and standards have to exist and to be adopted by each country for any product. Consumers must be protected from any damage that could be caused by the product. Fundamental right of every consumer should be the availability of necessary information to protect their own health and safety. Systems of environmental evaluation and labelling are implemented, which claim that the product (in concordance with the recent knowledge) process parameters minimizing or eliminating its negative environmental impacts. Product labelling is an option to reduce the risk and provide some form of assurance that products are safe. This paper discuses the present state and perspectives of ecolabeling lined from research hypothesis based on the results of a study from surveys oriented to interest of customers for buying environmental suitable products.
\end{abstract}

Keywords: labelling; environment; quality; safety; product; policy

\section{Introduction}

Quality and safety of products determines the success of all manufacturers, too. Therefore is important to ensure that the produced products have to the high quality and do not pose a danger either to people or to the environment. The product design becomes a key issue focused on development of such parameters, which will minimize or eliminate negative impacts to the environment even before its placement to the market [2].

The decisive factors are quality, compatibility, transparency and trust ability of the programmes, increase of the environmental awareness of the producers, consumers as well as the public, information availability, and mutual acceptance of the programmes in the international frame. Systems of environmental evaluation and labelling are implemented, which claim that the product process parameters minimizing or eliminating its negative environmental impacts. 


\section{Product policy}

Product policy results from the main elements, giving its conceptual development, political elaboration and implementation, i.e. aims and strategy, tools, subjects and products [13]. All those main elements influence selection of the parameters, which are supposed to minimize or eliminate negative environmental effects of a product. Environmental product policy aims and strategy are focused to the sustainable development principles at present, as they were defined by the report „Our Common Future“ (Brundtland G.H., 1991) and confirmed by the Rio summit in 1992. Certain change of the model concepts appears at present as described by the following Figure 1.

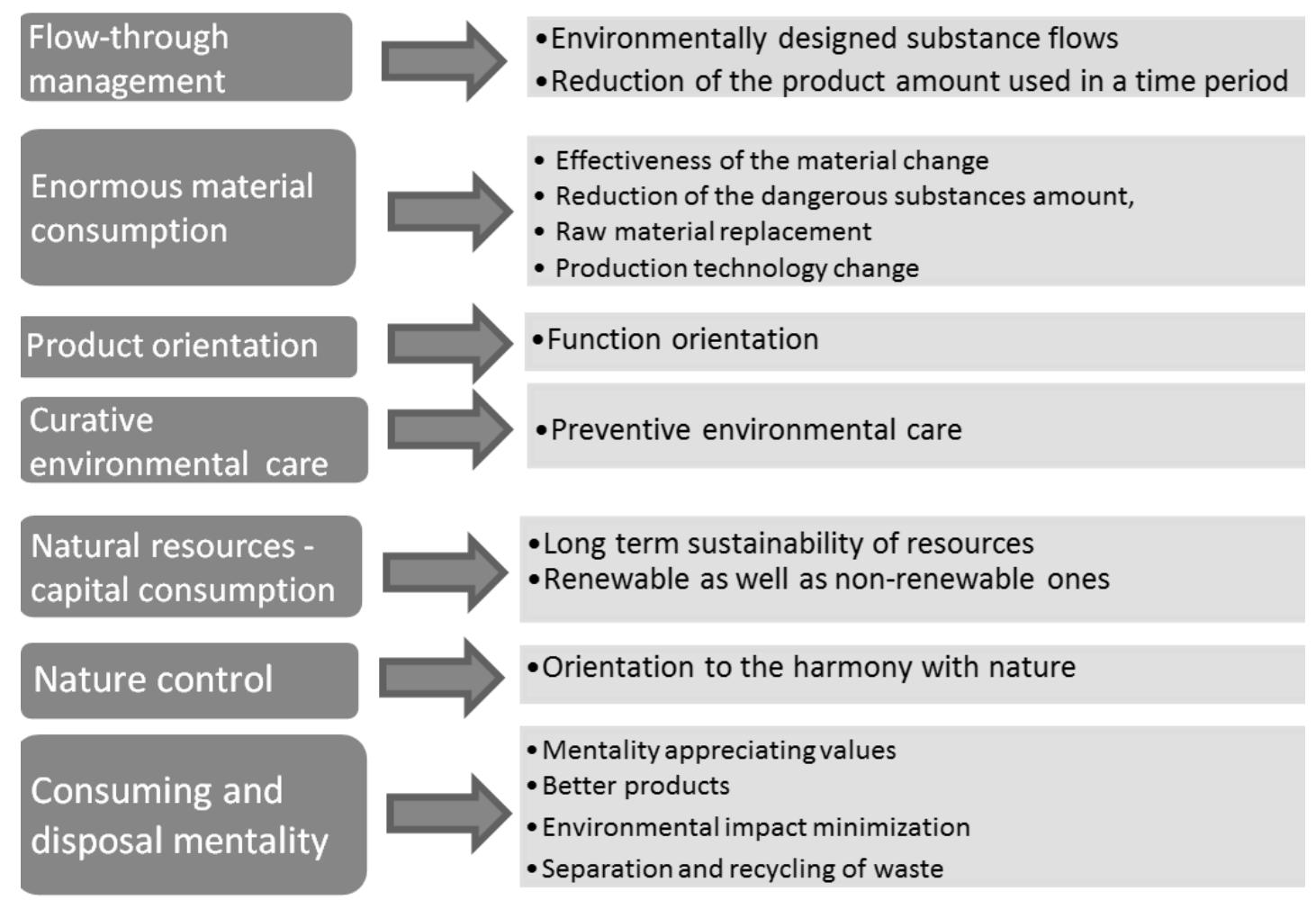

Fig. 1. Change of the model concepts in the environmental policy Equations

\subsection{Environmental policy}

Broadening trends of the indirect tools and emphasis to the voluntary information tools appear in the environmental product policy. These tools are extensively based on the voluntary activities of the producers, as well as increased environmental awareness of the public. Systems of environmental evaluation and labelling are implemented, which claim that the product (in concordance with the recent knowledge) process parameters minimizing or eliminating its negative environmental impacts. Implementation of such systems results not only from initiatives and requirements of the state administration, but also from the engagement of the producers and consumers [4].

The questions of different Eco labelling programmes development are dealt by several important international organizations, e.g. International Chamber of Commerce - ICC, World Trade Organization - WTO, United Nations Environmental Programme - UNEP, who assess and investigate the implemented environmental labelling programmes and who also evaluate their efficiency and effectiveness. Ecolabelling is now a very useful tool to encourage environmental practices for governments and to identify and establish markets i.e. domestic and international for industries to promote their environmentally preferable products. Many countries have adopted some kind of eco mark, while others are considering program development.

\subsection{Integrated product policy}

In recent times, the European Commission (EC) has been placing an emphasis on promoting a so-called Integrated Product Policy (IPP). IPP as defined by the EC aims to support the realisation of environmental product innovations in order to achieve a broad reduction of all environmental impacts along a product's life cycle (EU, 2001). The background is that all industrial goods cause environmental degradation in some way, whether from their manufacturing, use or disposal. IPP might be better termed "environmental product policy". It is an attempt by the European Commission to 
create conditions in which environment-friendly products, or those with a reduced impact on the environment, will gain widespread acceptance among the European Union's member states and 380 million consumers. Aspects of IPP:

- Involves many different actors such as designers, industry, marketing people, retailers and costumers

- Attempts to simulate each part of these individual phases to improve their environmental performance

- Is based on a variety of tools - both voluntary and mandatory

- Include e.g. economic instruments, environmental labelling and product design guidelines.

Integrated product policy is a key strategy for EU environmental policy to minimise environmental impacts by looking of all phases of a product life cycle and taking action it is most effective. The Cradle to cradle philosophy is an important part of the integrated approach that help to [9]:

- Increase reuse and recycling

- Increase the use of renewable energy and reduce $\mathrm{CO}_{2}$ emissions

- Increase sources, material and water recycling

- Develop and produce innovative and greener products.

Initiatives concerning IPP are largely due to the fact that traditional additive environmental protection has increasingly reached technical and economic limits. Moreover, increasing importance of the phases of consumption, disposal, extraction of raw materials and the using waste of production process, Figure 2.

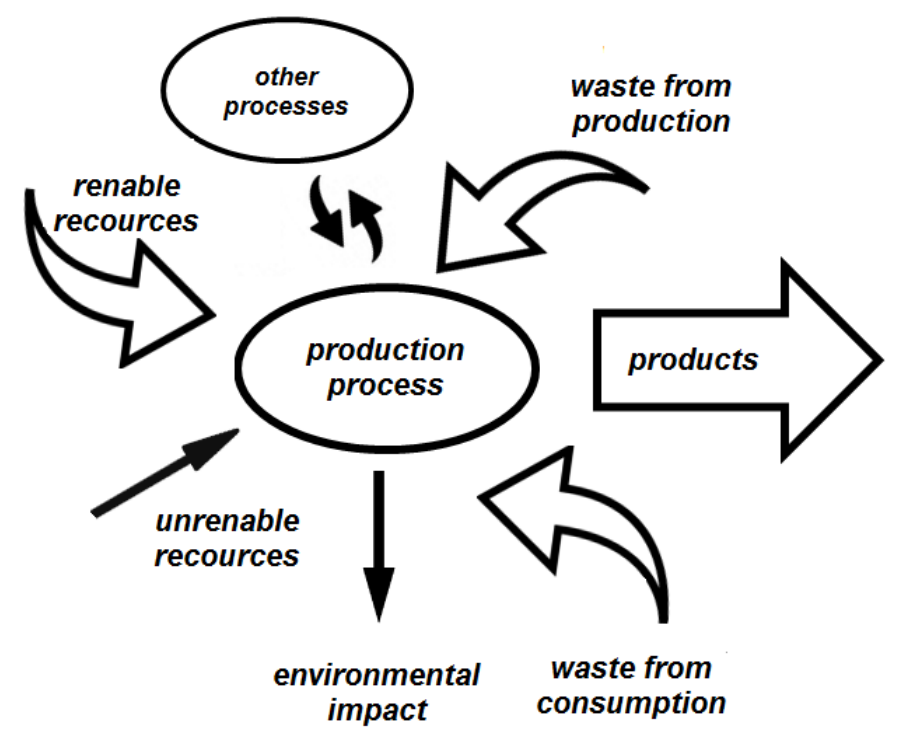

Fig. 2. Environmental suitable production process

Due to the heterogeneity of products, IPP cannot just consist of one general policy instrument, of course. Instead, there is a whole variety of measures that can be used to achieve the IPP objective, e.g., standards or so-called soft environmental policy instruments such as activities regarding voluntary agreements or environmental labelling. Concerning the latter, some companies already apply some of these voluntary environmental organisational measures. Indeed, despite the Green Paper on IPP published by the EC, which outlines proposals for the promotion of an IPP, it is still not well understood which factors and environmental policy instruments influence the environmental performance of products in general (EU, 2001 and EU, 2003), and thus environmental product innovations in particular [7].

\section{Marks and labelling}

The label may by one of the instruments of sustainable development, environmental and safety policy. In the field of environment and safety, there is an effort to make marks universal, e.i. , to have the same meaning in different social cultures.Marks notice about the level of quality (should be stable) and the reliability of the product (product, respectively service), and thus help to consumers make decisions what to buy more comfortable. Among other things, it also contributes to increase loyalty of customers. Marks make the cooperation and communication between dealers, distributors and producers more effective[10]. The symbol has the form of a geometric element. It represents a medium of receiving the relevant information to mediate the knowledge. Symbols indicate the importance assigned to them in opinion system (labelling scheme) to the consumer [1].

Products which are intended entirely to be used and get on the consumer market should meet requirements of Directive 2001/95/EC. Every product which is placed on the market must be labelled. [12] 
European Conformity marking (CE) is a certification mark that indicates conformity with health, safety, and environmental protection standards for products sold within the European Economic Area (EEA). The CE marking is the manufacturer's declaration that the product meets the requirements of the applicable EC directives. The letters "CE" are the abbreviation of French phrase "Conformité Européene" which literally means "European Conformity". The term initially used was "EC Mark" and it was officially replaced by "CE Marking" in the Directive 93/68/EEC in 1993.The CE mark certifies compliance of the product with the EU legislation and thus enables free movement of product within the European market. By placing the CE marking on a product producer declares his responsibility that the product complies with all the legal requirements for CE marking, which means that the product can be sold by throughout the European Economic Area (EEA, 28), EU Member States and countries of the European Free Trade Association (EFTA), namely Iceland, Norway and Liechtenstein. The European Commission thus refers to the CE Marking as a "Passport" which allows products to be freely circulated within the EU single market.

The EC declaration of conformity is the written statement and the a single declaration drawn up by the manufacturer to demonstrate the fulfilment of the EU requirements relating to a product bearing the CE marking he has manufactured. The declaration shall be in respect of all Community acts applicable to the product containing all information required for the identification of Community harmonisation legislation to which the declaration relates. It concerns the European Union (EU) Ecolabel which is a voluntary environmental labelling scheme. By means of transparent ecological criteria, it enables consumers to make conscious choices without compromising on the quality of the products. Other very important labelling of products placed on the market are:

- CE "European Conformity" marking

- Slovak Conformity mark CSK (in Slovakia)

- Quality brand SK.

Slovak Conformity mark (CSK) particular product certifies that the properties of a product meets the technical requirements for the product and in the case of construction products and technical requirements have been complied with and the conformity assessment procedures. Quality brand SK is owned by the Ministry of Agriculture and Rural Development, and was put to use in 2004, when program to support agricultural products and foodstuffs was established [11].

\subsection{Ecolabelling}

A 2010 Commission decision (Decision 2010/709/EU) was established the European Union Ecolabelling Board EUEB. Its members are appointed by the Commission. It is composed of representatives from the EU countries and the European Economic Area, as well as from certain European organisations representing, for example, consumers, business and environmental concerns. The Commission consults the EUEB when developing or revising the award criteria and requirements of the label. The Commission has adopted a series of decisions establishing ecological criteria for the awarding of the EU Ecolabel to different types of products; for several of these, the validity period expired by the end of December 2016. The Ecolabel covers a wide range of product groups such as cleaning products, appliances, paper products, textile and home and garden products, lubricants and services such as tourist accommodations [8]. To qualify for the Ecolabel, products have to comply with a tough set of criteria[15]. These environmental criteria, set by a panel of experts from a number of stakeholders, including consumer organisations and industry, take the whole product life cycle into account - from the extraction of the raw materials, to production, packaging and transport, right through to use and disposal/recycling. This life cycle approach guarantees that the products' main environmental impacts are reduced in comparison to similar products on the market [14].

The EU Ecolabel is a voluntary scheme, established in 1992 to encourage businesses to market products and services that are kinder to the environment. Countries or regions have their own eco-labels, which help customers to identify environmentally friendly products, Fig.3.

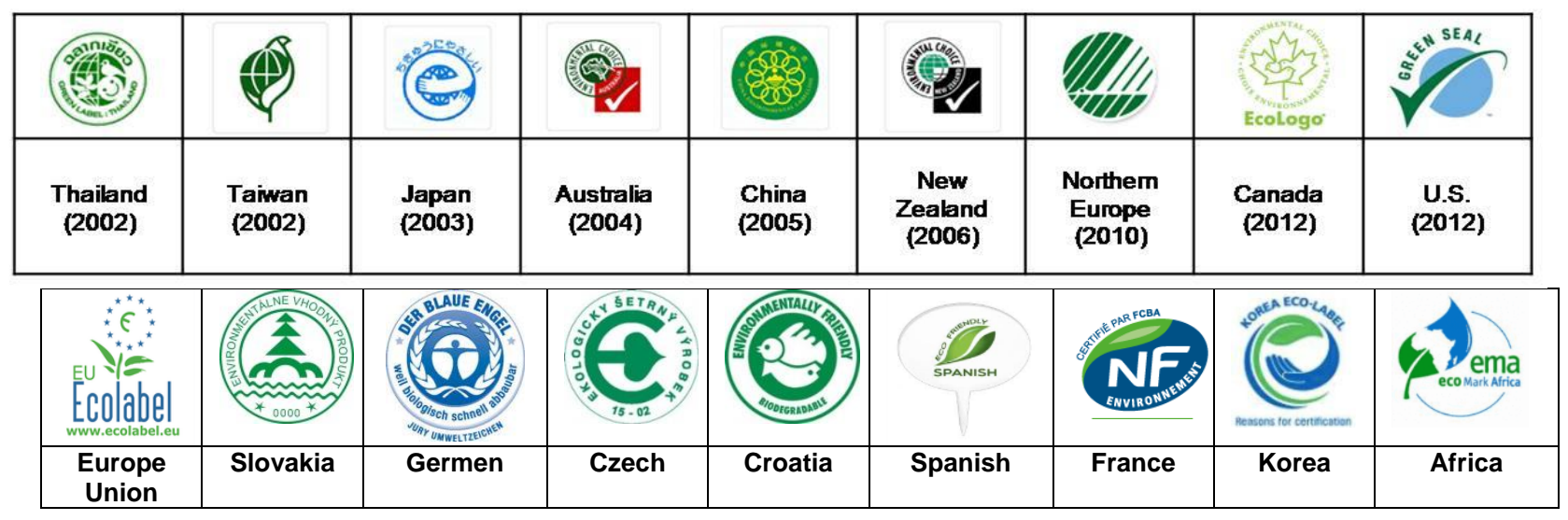

Fig. 3. Examples of eco-labels in the world 


\section{Knowledge and Information about the Ecological Behaviours, Research hypothesis}

Based on the theoretical perspective, research hypothesis are drawn in order to compare the results of a study from surveys oriented to interest of customers for buying environmental suitable products. Several surveys have been carried out to determine the level of consumer awareness of environmental labels in the SR [5], [11]. Respondents answered the question "In which area would you prefer environmentally friendly products?" From a questionnaire surveys conducted in Slovakia in 2012, which dealt with the perception of environmental labelling of products by Slovak consumers suggests that most respondents would prefer environmentally-friendly products in vehicle, paint and varnish groups, cleaners, batteries and services (Figure 4).

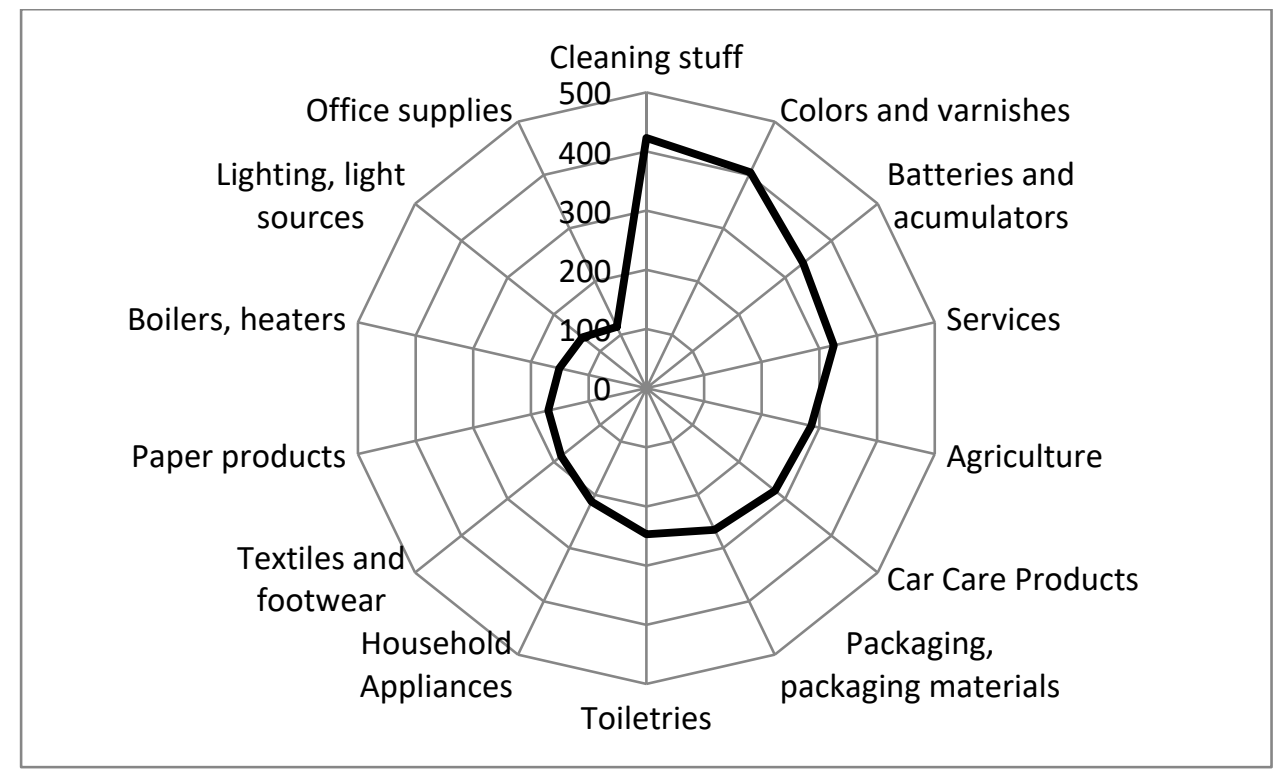

Fig. 4. Preferences of environmentally friendly products according to use field

As another example in Europe we introduce the survey in Germany (2009, Fig. 5) ilustrating answers of costumers on question: "Are you willing to pay more evironmentaly bening products". Note form questonary survey shows, that does not mean, that green products have to more costly [5].

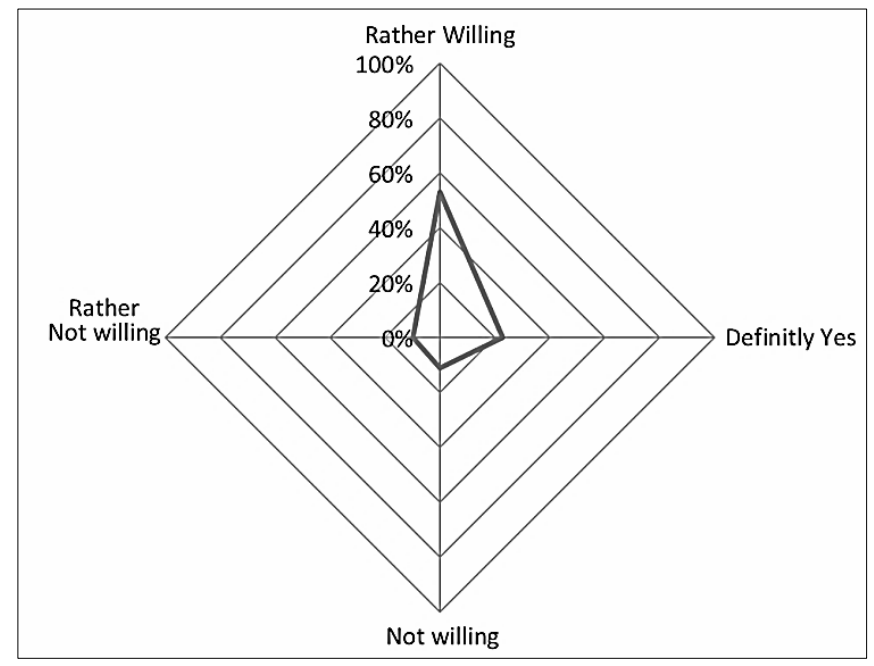

Fig. 5. Results of a study in Germany

Next, Nielsen's 2014 Global Survey shows that $55 \%$ of global online consumers across 60 countries are willing to pay more for products and services from companies that are committed to positive social and environmental impact [6]: Globally, more than half (52\%) of respondents said they have purchased at least one product or service in the past six months from a socially responsible company. Four in 10 respondents in North America and Europe said that they have made a sustainable purchase in the past six months. $52 \%$ of global respondents said that their purchase decisions partly 
depended on packaging, i.e. they check labelling to ensure that the brand is committed to positive social and environmental impact. This impacted decisions to a lesser degree in North America (32\%) and Europe (36\%).

Consumers in Asia-Pacific response that they had spent more on products and services from socially responsible companies. In Peru $62 \%$ of respondents said they would be willing to spend more, just 42 percent said they had actually done so. In Hong Kong 52\% respondents said they would be willing to spend more, just $32 \%$ said they had actually done so. In Slovakia, while $50 \%$ of respondents said they would be willing to spend more, just $22 \%$ said they had actually done so. Similar spreads existed in Bulgaria (53\% willing, but $31 \%$ had).

Nielsen found that $43 \%$ of global respondents claim to have actually spent more on products and services from companies that have implemented programs to give back to society ( $7 \%$ fewer than those who say they would simply be willing to pay). According age of respondents were results:

- Millennials (age 21-34) constituted 51\% of global respondents who would pay more for sustainable products and check packaging for sustainable labelling.

- Regionally, in the developing world (Asia, Middle East, Africa), there were wide gaps with respondents (age 21-34) in favour of sustainability actions on average three times more agreeable to sustainability actions than respondents (age 35-49) and 12 times more agreeable than (age 50-64) respondents.

From the studies based on questionnaire surveys has been report that higher price outweighed ethical considerations in case of purchase of green products. Lack of economic resources of consumers was found to magnify the effect of price and act as a barrier to purchase of green products and low price sensitivity of consumers was found to positively affect green purchase behaviour. Conversely, high price sensitivity negatively affected green purchase behaviour of consumers. It is thus clear that high price negatively influences green purchase intention and behaviour.

Previous studies revealed that, the consumers 'purchasing decisions are significantly affected by the consideration of the product impacts on the environment, and based on this empirical evidence should be highlighting the significant role of eco-labels in increasing the perceived behavioural control in consumers, too [3].

\section{Conclusion}

The main objective of environmental labelling is to generate demand for products with the lowest environmental impact. The aim of the research was to point to the ever-increasing environmental awareness of consumers who often have the problem of buying what they really want. In today's competitive environment, almost every organization seeks to promote its product as "environmentally-friendly", so governments, the industry and environmental NGOs have developed eco-labels to help consumers choose the "right" product.

Recent emergence of green trends has created a brand-new generation of environmentally concerned consumers and attracted attention of many companies worldwide. Green consumers have brought new market niche for business. Ecolabelling is known as one of the most popular tools of green marketing worldwide. Customers should trust the company offering eco-labelled products, because such company should be green in its everyday activities, i.e. to reduce the waste, reduce, and recycle. Therefore, the role of consumers in such a scenario becomes crucial in guiding the production paths [1], since these can directly influence the environmental impact of a product in the phases of use and end of life (way of functioning, separation of waste, collection, recycling), and exert pressures on producers to take environmental criteria into account starting from the design and production processes of the environmentally friendly products.

Fundamental right of every consumer should be availability of necessary information to protect their own health. Information should be obtained from the marks referred to the product which it comes into contact. Marks are an integral part of everyone's life. We can see various types of marks at home, in stores and everywhere around us. Symbols indicate the importance assigned to them in opinion system (labelling scheme) to the consumer.

Eco-design, LCA, Eco labelling and green marketing as a voluntary regulative tools of the environmental policy are significant instrument for the increase of abilities of the organization competitive. Their using is important for the organizations with established EMS by ISO 14001, thus EMAS, which contracted to the continual release of negative impacts of its activities on the environment. Abroad, during the period of its existence, Eco labelling has entered not only the minds of customers, but also became an inevitable part of advertisements of producers and importers introducing appropriate brands of environment-friendly products into the market.

Products available on the market should be healthiness and should not threaten human life and the overall safety of the consumer and does not pollute the environment. This means that security specifications and standards have to exist and to be adopted by each country for any product. Consumers must be protected from any damage that could be caused by the product. Based on the knowledge the consumer creates an own personal value of product quality which helps during the process of making decision about buying the product. All external and internal features and characteristics of the product affect the consumer behavior .Important role in consumer behaviour is a safety and environmental labelling and brand. Provides a means of receiving the relevant information for the purpose of mediation of knowledge. Basic right of every consumer's need for information to enable it to protect their own health. Information obtained from the brands mentioned on the product with which it comes into contact.

Supervision and inspection the market is more and more difficult. It has to be clear that products situated in the market and stores are not absolutely risk free. Not sufficient or incorrect information can be present on the product which can endanger the customer's health. 
Many countries have adopted some kind of eco mark and the results achieved show that well organized programmes of environmental evaluation and labelling may serve as an effective tool not only for the environmental protection policy, but also for the trade policy.

Despite the fact that in SR there was no campaign about the Eco labelling programme it is sensible to label the products because it strengthens the feeling of the public about the environmental protection. By means of environment-friendly product labelling the Slovak customers get guaranteed information about the products respecting the environment. The problem of successful implementation of environmental label in Slovakia is especially the provision and availability of information about the products. Future research will focus on monitoring the sale and purchase of environmental friendly products in Slovakia and these comparisons with the developed countries of Europe.

\section{Acknowledgments}

This paper is a result of research in the frame of the project KEGA 048TUKE-4/2015 "Transfer of knowledge from scientific-research activities into multimedia education process" provided by the Ministry of Education, Youth and Sports of the Slovak Republic.

We are grateful to the partner MtF of the Slovak Technical University of Trnava as member of the project VEGA 1/0990/15 "The readiness of industrial enterprises to implement the requirements of standards for quality management systems ISO 9001: 2015 and environmental management systems ISO 14001: 2014“.

\section{References}

[1] Daddi,T., Iraldo,F., \& Testa F.(2015) Environmental Certification for Organisations and Products: Management Approaches and Operational Tools, Business \& Economics.232 p.

[2] Draxlerova, M., Rusko, M. \& Kuracina, M. (2015): Labelling of textile products from the perspective of quality, maintenance, safety and environment. In Research papers Faculty of Materials Science and Technology Slovak University of Technology in Trnava. Vol. 23, No. 36 (2015), s. 57-64. ISSN 1336-1589.

[3] Ha H, Janda S. 2012. Predicting consumer intentions to purchase energy-efficient products. Journal of Consumer Marketing 29: 461-469.

[4] Hurt, U., Otto, T., Kaare,K., Koppel, O. (2014). New Approachto Knowledge Transfer Environment Development. In 24th DAAAM International Symposium on Intelligent Manufacturing and Automation, Procedia Engineering 69. pp. $273-281$.

[5] http://ec.europa.eu (2012) Flash Eurobarometer 367: Attitudes of Europeans Towards Building the Single Market For Green Products, Report, 2013, Accessed on: 2016-09-05.

[6] htpp://www.nielsen.com(2015) What People Watch, Listen To and Buy. Nielsen Accessed on: 2016-08-10.

[7] Krechovska. M.; Tausl Prochazkova. P. ( 2014 ). Sustainability and its Integration Into Corporate Governance Focusing on Corporate Performance Management and Reporting. In DAAAM International Symposium on Intelligent Manufacturing and Automation, Procedia Engineering 69. pp. $1144-1151$.

[8] Pedersen E.R, \& Neergaard P.( 2006.) Caveat emptor-let the buyer beware! environmental labelling and the imitations „Green“ consumerism. Business Strategy and the Environment Vol.15, pp. 15-29.

[9] Polankova, M., Manlig, F. \& Kralikova, R. (2015). Environmental reporting in the enterprise and related issues. In. MM Science Journal, 10/2015, pp. 691-695.

[10] Pujari, D. (2006) Eco-innovation and New Product Development: Understanding the Influences on Market Performance. Technovation. Vol. 26. Issue 1. pp. 76-85. ISSN: 0166-4972.

[11] Rusko, M., Chovancova, J. (2008) Consumers`Awareness about Eco-Labels Type I. In Environmental Management for Education and Edification. Vol. 5, No. 2 s.23-34. ISSN 1336-5762.

[12] Rusko, M.; Kralikova, R.; Mikulova, M. \& Ilko, J. (2016). Labeling of Products from the Context of Environment, Quality and Safety, Chapter 37 in DAAAM International Scientific Book 2016, pp.419-434, B. Katalinic (Ed.), ISBN 978-3-902734-09-9. ISSN 1726-9687, Vienna, Austria.

[13] Rehfeld, K.M., Rennings, K. \& Ziegler, A.(2007). Integrated Product Policy and Environmental Product Innovations: An empirical Analysis. Ecological Economics, Volume 61, Issue 1, pp. 91-100.

[14] Testa, F., Iraldo, F., Vaccari, A. \& Ferrari, E. (2015), Why Eco-labels can be Effective Marketing Tools: Evidence from a Study on Italian Consumers. Business Strategy and the Environment. Vol. 24, pp. 252-265. doi: $10.1002 / \mathrm{bse} .1821$.

[15] ISO Central Secretariat. (2012) Environmental labels and declarations. How ISO standards help. Genève. 25 p. ISBN 978-92-67-10586-4. 